\title{
A mídia televisiva e a transmissão de valores na ótica de alunos do Ensino Médio
}

\section{The media and television transmission of values in the view of High School students}

\author{
Clésia Maria Hora Santana ${ }^{1}$ \\ Luis Paulo Leopoldo Mercado ${ }^{2}$
}

\begin{abstract}
RESUMO
Esse estudo identifica a percepção de jovens do Ensino Médio de duas escolas públicas localizadas em um município do interior do Estado de Alagoas quanto aos valores transmitidos na mídia televisiva. Identifica o perfil desses jovens e a programação por eles preferida nessa mídia. Tratase de uma pesquisa de campo em duas escolas da rede pública estadual, da qual participaram 87 alunos. $\mathrm{O}$ instrumento utilizado foi o questionário com perguntas abertas e fechadas. Conclui-se que se faz necessária a discussão da temática na escola e que o poder dessa mídia não seja ignorado pelos professores, contribuindo para a reflexão acerca dos valores por ela disseminados.
\end{abstract}

Palavras-chave: valores; mídia televisiva; escola.

\begin{abstract}
This study identifies the perceptions of young high school students from two public schools located in a city in the state of Alagoas about the values transmitted in the television media. It identifies the profile of these young people and their favourite programme in this media. This is a field research
\end{abstract}

${ }^{1}$ Mestre em Educação Brasileira pela Universidade Federal de Alagoas (UFAL). Professora de Educação Básica e Técnica Pedagógica na Diretoria Regional de Educação de Sergipe, Brasil. e-mail: clesiahora@gmail.com

${ }^{2}$ Doutor em Educação (PUC/SP), Professor Associado III vinculado ao Programa de Pós-Graduação em Educação da Universidade Federal de Alagoas (UFAL), Brasil. e-mail: luispaulomercado (a) gmail.com 
in two public schools in the state, attended by 87 students. The instrument used was a questionnaire with open and closed questions. We conclude that it is necessary to discuss the topic at school and not to ignore the power of this media by teachers, contributing to a reflection on the values disseminated by it.

Keywords: values; television media; school.

\section{Introdução}

Na sociedade contemporânea, os interesses pessoais parecem entrar em conflito ou se sobreporem aos da sociedade, contribuindo para a existência de uma moral difusa, na qual tem predominado o individualismo ou os interesses de pequenos grupos que desejam impô-los aos da coletividade visando normalizá-los. As relações tornam-se fluidas, inconstantes (BAUMAN, 2001), os laços se dissolvem ou inexistem, os valores e crenças são abandonados. Os avanços tecnológicos ocorridos nas últimas décadas têm promovido mudanças sucessivas e nada parece adquirir um caráter permanente. A sucessão de acontecimentos e a rapidez com o qual são esquecidos e substituídos têm contribuído para reforçar a pouca memória acerca dos fatos do cotidiano.

De acordo com Chauí (2000), somos educados para conviver com os valores impostos pela sociedade e aprendemos a servi-los desde cedo, visando à manutenção de determinados padrões sociais considerados aceitos. Nesse sentido, a ética é também uma criação cultural e social, visto que cada sociedade, de acordo com sua cultura, cria conceitos acerca do que é ético ou antiético, fazendo com que se torne necessário conhecer as concepções de cada cultura, a fim de evitar tecer julgamentos sem fundamento ou, ainda, desrespeitar atitudes culturalmente aceitas.

Para Chauí (2000), a consciência e o senso moral se relacionam, já que ambos se referem aos valores, sentimentos e ações que se referem ao bem e ao mal, fazendo parte da nossa vida, visto que são inerentes, intrínsecos, aos relacionamentos que desenvolvemos ao longo da vida e na forma de lidar com o outro. Para a autora, valores sociais como honestidade, honradez e justiça, assim como sentimentos que esses valores provocam, tais como: admiração, vergonha, dúvida, entre outros, relacionam-se diretamente com o senso comum e a consciência. De acordo com a autora, "os valores morais modificam-se na História porque seu conteúdo é determinado por condições históricas". (CHAUÍ, 2000, p. 448).

Este estudo objetiva conhecer o perfil dos jovens de Ensino Médio de duas escolas públicas localizadas em um município do interior do Estado de 
Alagoas. Investigou-se a programação preferida desses jovens na mídia televisiva e suas opiniões sobre os valores transmitidos por essa mídia, assim como os valores que percebem no seu entorno. Para atingir o objetivo, realizouse uma pesquisa de campo em duas escolas da rede pública estadual, no município de Porto Real do Colégio, localizado no Estado de Alagoas. O instrumento utilizado foi um questionário com perguntas abertas e fechadas, algumas das quais se apresentaram como afirmativas, em que o participante emite julgamento através de uma escala do tipo Likert, de cinco pontos, com diferentes graus de intensidade para um mesmo item. Não foram efetuadas comparações entre os alunos das duas escolas, visto que ambas pertencem à rede pública estadual de ensino e possuem jovens advindos de realidades socioeconômicas similares. A opção pelas duas escolas deu-se por se tratar das únicas escolas que ofertam o Ensino Médio no município e, também, pela possibilidade de obter uma amostra maior, já que uma das escolas somente este ano começou a ofertar o Ensino Médio, tendo, portanto, uma quantidade alunos matriculados ainda pequena.

\section{Revisão teórica}

Ao longo da história da civilização humana, o homem age sobre a natureza, sobre si mesmo e sobre os outros, constituindo as denominadas relações sociais, entendendo-se aí suas relações materiais e espirituais, nas quais suas razões são criadas e recriadas. Nesse prisma, a moral é um sistema de normas, princípios e valores que norteiam, regulamentam as relações entre os indivíduos na sociedade. Essas normas estão imbricadas, internalizadas no homem enquanto ser social ao longo da sua história e passam a ser acatadas conscientemente, segundo as suas convicções internas, com as quais a ética se depara (BRITES et. al., 2007). De acordo com o pensamento aristotélico, "a ética e a virtude são hábitos que se consolidam com a ação, portanto não são ensinados como o saber teórico. Antes seria um conjunto de costumes que deveriam ser reiteradamente exercitados." (TAGATA, 2008, p. 120).

Michel (2005) distingue quatro concepções de ética, a saber:

a) Ética da convicção pessoal - caracterizada pelo conjunto de valores que constituem o caráter, a personalidade de cada um, contribuindo para a formação da moral individual e da orientação desse indivíduo na sociedade;

b) Ética do grupo social ou da responsabilidade - caracterizada pelo conjunto de valores que são determinados pelo grupo social ou cultura de um povo, orienta os interesses e o comportamento desse grupo. Segundo a autora, 
os valores que correspondem à ética do grupo nem sempre correspondem aos valores individuais, à ética individual; no entanto, para que o indivíduo possa continuar a pertencer a esse grupo, tende a assumir esses valores como seus;

c) Ética do valor absoluto - caracterizada pelo grupo de valores considerados válidos para toda e qualquer situação. São inquestionáveis, não admitindo exceções, resistindo a pressões ou a qualquer outra situação;

d) Ética do valor relativo - caracterizada pelo conjunto de valores considerados válidos para uma determinada situação. Esses valores podem variar segundo os agravantes ou atenuantes, determinando seu valor e importância. Segundo a autora, é a "ética do depende", segundo a qual o julgamento depende das variáveis interferentes. (MICHEL, 2005, p. 14).

Vivemos no interior do mundo cultural, cuja rede de significações nele imbricada nos antecede e modela os nossos comportamentos através de costumes e valores previamente estabelecidos, que podem ser transformados através da reflexão constante, acrescentando os que formaremos ao longo da vida, por meio de novas informações e reflexões, revendo-os ou reafirmando-os (PONCE, 2009). Para Severino (2001, p. 92), "os valores se impõem como força normativa e prescritiva, quase que ditando como e quando as ações devem ser conduzidas. Não segui-las dá a sensação de que se está agindo errado, embora os sujeitos mantenham um nível proporcional de liberdade ante a norma".

De acordo com Jales (2010), faz-se necessária uma democracia da ética, na qual todos se comprometam com todos, em que nenhuma etnia, religião ou país se considere superior e se isole da diversidade, da multiplicidade de manifestações culturais, na qual a busca pela convivência harmoniosa seja um pacto de todos os homens.

Os indivíduos de cada sociedade comportam-se e diferenciam-se de acordo com seus costumes, nos quais se manifestam os seus valores. Logo, valorizar não é um gesto inato, é "relacionar-se com o mundo não se mostrando indiferente a ele, dando-lhe uma significação." Nesse sentido, a educação mostra-se necessária para a construção de valores, visto que "refletir e posicionar-se são habilidades que precisam ser adquiridas, são passíveis de aprendizagem". (PONCE, 2009 , p. 9). E as orientações dos professores contribuem para o desenvolvimento da reflexão crítica dos alunos, buscando instigá-los desde cedo à busca da verdade e da justiça, robustecendo os pilares da construção ética do cidadão, visando equilibrar percepções diferentes, no respeito à vida humana, no respeito à integridade física, às diferenças sociais, culturais e raciais.

No Brasil, no final da década de 1990, como parte da política do governo 
federal, foram elaborados os Parâmetros Curriculares Nacionais (PCN), que visavam auxiliar a escola na construção da autonomia e da cidadania dos alunos. Esse documento torna-se público em 1997 e 1998, tendo em pauta a formação de um indivíduo ético, pleno, contemplando a educação moral, a ética, os valores e a pluralidade. Contudo, embora tenham significado um avanço por possibilitarem a reflexão teórica sobre o tema, na ótica de Ponce $(2010$, p. 8$)$ a discussão para a construção de uma educação em valores não foi aprofundada na prática e esse "documento esteve distante da escola para a qual se destinava, tendo um desencontro com ela ou, na melhor das hipóteses, um encontro superficial". Desse modo, a ética "continuou a não ser contemplada, de modo especial e sistemático, na formação de alunos e professores".

Para Auad (2005), os idealizadores do texto dos temas transversais esperavam que os mesmos fossem debatidos no interior das disciplinas e não em apenas uma área do conhecimento ou novas áreas; eles perpassariam todas as áreas, ocupando igual importância que as demais áreas dos PCN. Segundo a autora, esses temas são tratados de forma ambígua ou silenciados nas práticas escolares, o que pode ter contribuído para reforçar essa lacuna na formação docente e ser a razão pela qual desenvolver um "projeto de educação comprometida com o desenvolvimento das capacidades que permitam intervir na realidade para transformá-la" (PCN, 1998, p. 24), proposto na apresentação dos temas transversais, esteja distante da prática de muitos professores, e o próprio documento reconhece essa lacuna na formação docente para lidar com as questões propostas, todavia não menciona alternativas para suprimir o problema da formação docente. Considerando que a ética e a moral permeiam a conduta humana, quer na vida pessoal quer na vida profissional, faz-se necessário refletir acerca dos valores morais e da relevância que estes adquirem na sociedade e como são percebidos pelos jovens nela inseridos, assim como os valores disseminados na mídia televisiva brasileira.

No cenário brasileiro, tornou-se comum a exibição de programas televisivos cujos conteúdos são questionáveis para a formação ética da sociedade. Sequestros são exibidos ao vivo, em tempo real, como parte da programação dos canais, brigas em família e narrativas de crimes são exibidas como se fossem documentários, a sociedade do espetáculo banaliza crimes e cenas de violência. Flagrantes de corrupção em todas as esferas são, muitas vezes, divulgados e premiados com a impunidade, normalizando-a. O dinheiro e a posição social parecem ditar as normas, num inconteste desrespeito ao preceito constitucional no qual todos são iguais perante a lei.

Segundo D'Ávila (2003, p. 2), a mídia televisiva usa diferentes estratégias na disputa contínua pela audiência, visando assegurar ou elevar os índices do 
IBOPE, desarticulando concorrências para permanecer aceita pela opinião pública. Para a autora, atitudes e desajustes injustificáveis que têm sido "observados no lar e na sociedade, demonstram um comprometimento com a distorção de valores absorvidos dos meios de comunicação, o televisual como líder na preferência", com sua programação diária afetando toda a sociedade, revelando todo o seu poder de persuasão e de banalização dos valores, e aquela que "cumpre com os papéis cultural e educativo, moral e ético não representa, infelizmente, um número vultoso", o que nos leva a perceber que:

A cultura moderna fez "tábula rasa" dos valores e conceitos, não se pronunciando sobre as noções do que é certo e do que é errado, cultuando muitas vezes o errado, em detrimento do certo. Tem-se, como exemplo, novelas que fazem apologia dos desajustes familiares e sociais, com cenas constantes de sexo e programas, em grande escala, que cultuam a violência, dos filmes para adultos aos desenhos infantis, onde, após inúmeras agressões, o personagem mau sai sempre vitorioso, obtendo vantagens, gozando de prestígio etc. (D’ÁVILA, 2003, p. 10)

Nesse sentido, ressalta-se a importância de que essas temáticas sejam objeto de reflexão em casa e na escola, na busca da valorização, da conscientização e da adoção de valores morais, éticos e sociais e a influência exercida pelo professor em sala de aula e o seu carisma devem ser explorados "para trabalhar com crianças e jovens, na abordagem inicial dos valores morais, axiologizando-os após, em conformidade com a necessidade e capacidade de apreensão de cada grupo". A pesquisadora sugere que sejam organizados debates com temas de interesse dos adolescentes, buscando avaliar tendências, carências, excessos e saturações. Essa abordagem interdisciplinar visa motivar e incluir momentos oportunos para compreender e aceitar "conceitos morais, sociais, cívicos, tão deturpados pela mídia, falhos e conflitantes em suas cabeças, gerenciando os destinos dessa juventude que representará o nosso país". (D’AVILA, 2003, p. 16).

A pesquisadora advoga a ideia de que apenas em grupo os jovens "alimentam o princípio do prazer, da identidade", todavia, quando permanecem sozinhos frente à televisão ou no computador, "tornam-se narcisistas, solitários", podendo perder "a capacidade de se projetar no outro", de dar e receber nas relações, da busca da alteridade. (D'ÁVILA, 2003, p. 15). Nesse cenário, crianças e adolescentes acompanham livremente a grade da programação desses canais, sem refletirem sobre seus valores, sobre o certo e o errado desses atos. Numa sociedade em que a individualidade e a competitividade parecem ditar as regras, na qual as relações tornam-se fluidas, passageiras (BAUMAN, 2001), faz-se necessário refletir sobre o papel da escola nesse contexto. 
Qual o perfil dos jovens que estão cursando o Ensino Médio na rede pública? Qual a sua concepção de valor? Quais os seus valores? Até que ponto os programas exibidos na televisão aberta contribuem para a transmissão de valores? Quais são os valores mais disseminados por essa mídia, na ótica dos jovens? Como a escola pode contribuir para a reflexão sobre os valores e o papel da mídia? Essas inquietações convergem na pergunta central desse estudo: qual a percepção de alunos do Ensino Médio de escolas públicas estaduais, em Alagoas, acerca dos valores transmitidos pela mídia?

Este estudo visa conhecer a percepção dos alunos de duas escolas de Ensino Médio no interior de Alagoas quanto aos valores transmitidos pela mídia; investigar o perfil de alunos do Ensino Médio de escolas públicas alagoanas; conhecer a programação preferida desses jovens e suas opiniões sobre os valores transmitidos por essa mídia.

\section{Metodologia}

Participaram da pesquisa 87 alunos do Ensino Médio de duas escolas da rede pública estadual, localizadas no município de Porto Real do Colégio, no Estado de Alagoas. A maior parte dos participantes encontra-se na faixa etária de 14 a 18 anos (74\%), os demais têm entre 19 e 23 anos (21\%) e 24 a 28 anos (5\%). $51 \%$ são do sexo masculino e $49 \%$ do sexo feminino, $95 \%$ são solteiros e $90 \%$ moram com os pais. No que tange ao credo religioso, $83 \%$ se declaram católicos.

Entre os jovens que compõem a amostra, 59\% estudam no turno noturno e $41 \%$ no vespertino, pouco mais da metade (53\%) está trabalhando, embora destes apenas $68 \%$ tenham a carteira de trabalho assinada e $51 \%$ afirme ganhar menos de um salário mínimo. Questionados sobre a atividade mais importante que fazem, hoje, $78 \%$ dos participantes acreditam que é estudar e afirmam que, se pudessem escolher a profissão, a escolha se daria pela realização profissional, segundo $40 \%$ dos participantes; contudo, para $31 \%$ o mais importante é o status, o prestígio que a profissão pode vir a proporcionar, e para $15 \%$ a remuneração é o elemento mais importante na escolha de uma profissão.

$\mathrm{O}$ instrumento da pesquisa foi um questionário com perguntas abertas $\mathrm{e}$ fechadas compostas por afirmativas, organizadas numa escala do tipo Likert, na qual os respondentes escolheram entre as cinco graduações de resposta, que variavam entre concordo completamente até o discordo completamente. As questões visavam identificar o perfil dos participantes, identificar a percepção de valores desses jovens, a programação preferida na mídia televisiva e os valores que eles percebem na mesma. 
Inicialmente, conversou-se com os diretores dos estabelecimentos de ensino, explicando-lhes os objetivos do estudo e solicitando-lhes autorização para a realização do mesmo. Em seguida, a pesquisadora conversou com os professores e posteriormente com os alunos, explicando-lhes sobre o estudo e a importância da participação dos mesmos. Foi apresentado e explicado o conteúdo do termo de consentimento livre e esclarecido e solicitada a assinatura dos que concordassem em participar da pesquisa. Após a assinatura e da recolha dos termos, foi feita a distribuição dos questionários, que foram lidos e respondidos pelos alunos fora do horário escolar. A devolução dos questionários, agendada para o dia seguinte à nossa visita, ficou definida com todos os alunos participantes da amostra, deixando explícito que apenas seriam devolvidos os questionários daqueles que concordassem em participar do estudo. Foram devolvidos 87 questionários dos 100 distribuídos.

\section{Resultados}

As respostas dadas pelos participantes indicam que $84 \%$ deles assistem à televisão todos os dias, sendo que $43 \%$ costumam passar de 1 a 3 horas do seu dia vendo a programação televisiva e, normalmente, estão sozinhos, conforme Gráficos 1, 2 e 3, corroborando a pesquisa feita por Arnaldo (2002), segundo a qual o deslumbramento pela TV e pela mídia em geral faz com que passem mais tempo em frente à TV do que fazendo as lições de casa. A TV é ainda apontada como mídia preferida por $63 \%$ dos participantes da pesquisa, seguida pela internet.

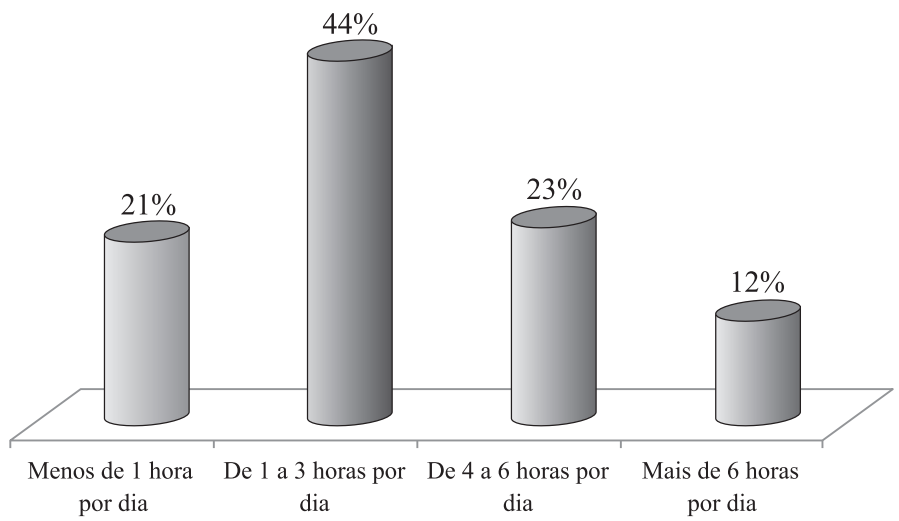

Gráfico 1 - Tempo médio diário assistindo à TV

Fonte: Autores (2010) com base nos dados da pesquisa 


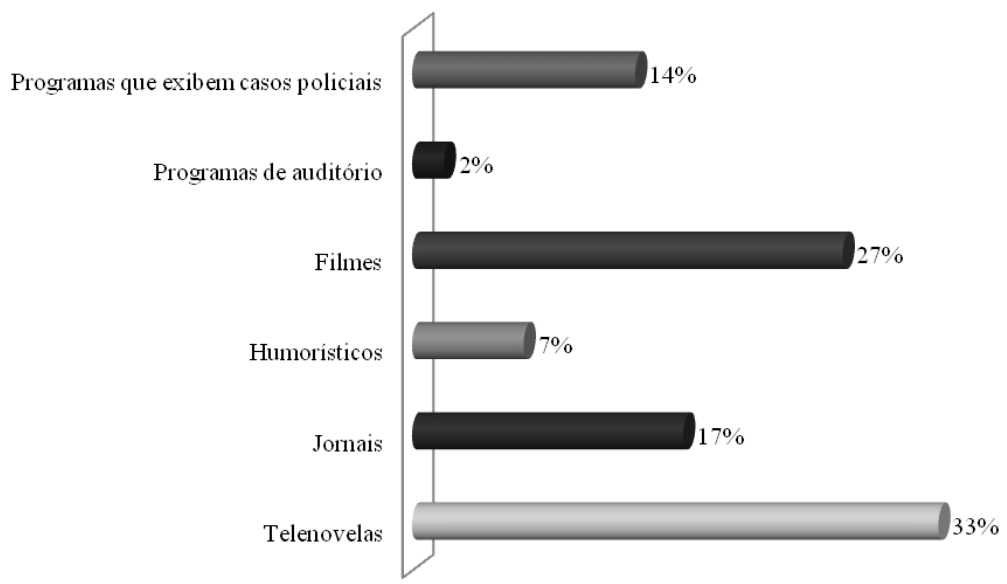

Gráfico 2 - Programa de TV a que mais assiste

Fonte: Autores (2010) com base nos dados da pesquisa

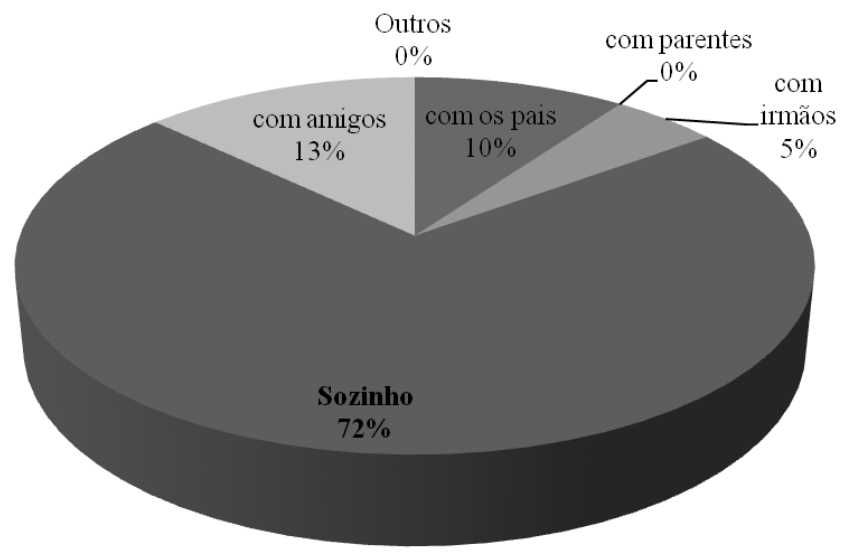

Gráfico 3 - Costuma ver TV

Fonte: Autores (2010) com base nos dados da pesquisa

A popularização dessa mídia pode ser perceptível também pelo número de casas com esse aparelho, todos os pesquisados possuem um ou dois aparelhos de TV em suas residências, mas apenas um dos pesquisados afirmou possuir em sua residência um computador com acesso à internet, embora grande parte 
(98\%) afirme que acessam-na ao menos uma vez por semana e geralmente (92\%) em lan houses, utilizando-a para fazer pesquisas (40\%), namorar (11\%), passar o tempo (3\%) e fazer compras (1\%).

Percebe-se a influência da televisão na vida desses jovens, o poder de atração dessa mídia, visto que a maioria passa uma ou mais horas do dia ou da noite vendo seus programas favoritos, como as telenovelas (34\%), que ditam moda, comportamento e paixões, os filmes (26\%) e os telejornais (14\%) que, segundo eles, os mantêm em contato com os fatos ocorridos no mundo.

Para esses jovens, as novelas fantasiam a vida real, mas não incentivam os laços familiares, a amizade e a lealdade. Segundo a opinião de $51 \%$ desses jovens, amizades verdadeiras já não existem e a honestidade, a igualdade e a justiça também são valores questionáveis na contemporaneidade. Os dados apontam que $62 \%$ deles não acreditam que a honestidade seja um valor dos dias atuais e $69 \%$ não acreditam na justiça brasileira, embora $78 \%$ tenham declarado acreditar em justiça.

Na ótica de Trindade (1999), novos valores têm sido dinamizados pela mídia e alimentado o novo modo de pensar dessa sociedade contemporânea, entre eles, a valorização do novo, da obsolescência dos objetos, da praticidade, da sensualidade.

Verificamos que 55\% acreditam que o consumismo, o desejo de possuir desde roupas até equipamentos tecnológicos, se deve à exposição desses produtos na mídia. Na opinião desses jovens, a TV não estimula a violência (66\%) e muitos consideram que veem mais cenas de violência em outros locais, como em bares (34\%) ou mesmo na rua (44\%), do que na televisão, todavia, não os correlacionam aos fatos exibidos cotidianamente nessa mídia. Apenas 34\% acreditam que os índices de violência podem ser influenciados pela programação televisiva e pela banalização da violência no cotidiano. Não é feita uma leitura crítica a esse respeito e nem esses jovens costumam conversar com seus pais sobre as cenas que presenciaram.

Questionados sobre a influência dessa mídia no comportamento violento desses jovens e nos casos de violência divulgados na mídia, os mesmos não as relacionam à influência dos programas televisivos, embora, admitam que os filmes de ação (48\%) e os telejornais (21\%) estão entre os programas que mais exibem cenas de violência. Segundo eles, a impunidade (24\%) e a ausência de leis mais rígidas (64\%) são os maiores responsáveis pelos índices de violência no país.

Percebe-se a falta de criticidade desses alunos, que têm na TV sua principal fonte de lazer, mas não percebem a banalização da violência, a influência nos seus sonhos de consumo e não associam as mensagens exibidas ao seu cotidiano. 
Verificou-se que os jovens participantes da pesquisa não são usuários de drogas, $92 \%$ nunca sequer experimentaram e $38 \%$ afirmam nunca terem ingerido bebidas alcoólicas, no entanto, $20 \%$ afirmam beber sempre nos finais de semana, $26 \%$ bebem "de vez em quando" e 16\% declaram beber raramente. Questionados sobre a influência da TV para o consumo de bebidas ou drogas, para 86\% ela não exerce qualquer influência para o consumo de álcool e $85 \%$ negam a sua influência para o consumo de drogas e entorpecentes.

Segundo Bourdieu (1997, p. 22), a televisão exerce uma forma particular de violência simbólica, na qual se obtêm a cumplicidade, a conivência dos que sofrem e dos que a exercem, visto que "são inconscientes de exercê-la ou de sofrê-la". Para esse autor, a guerra de audiência, a busca incansável e insensata pelo furo jornalístico gera "uma representação do mundo prenhe de uma filosofia da história como sucessão absurda de desastres sobre os quais não se compreende nada e sobre os quais não se pode nada" (BOURDIEU, 1997, p. 141), gerando a ausência de valores e de um público que não reflete e não anseia por uma moral, por um desfecho das histórias; as reportagens e as histórias se sucedem, se repetem e caem no esquecimento, como se nada significassem ou nada representassem, construindo o que Adorno (1995) denomina de espetacularização da imprensa.

A internet é apontada como a segunda mídia mais vista e utilizada pelos alunos, apenas 2\% afirmam não usá-la, os demais a utilizam uma vez por semana. Entre os que costumam usá-la, 92\% procuram uma lan house para acessá-la, o que talvez explique o fato de ainda não ser tão popular quanto a TV, embora já possua uma margem de preferência considerável. Quanto às formas de uso, $45 \%$ afirmam usar para conversar com amigos, $40 \%$ para fazer pesquisas, $11 \%$ para namorar, $3 \%$ para passar o tempo e apenas $1 \%$ para fazer compras. Nenhum pesquisado afirma usá-la para leitura, embora os textos e as leituras estejam presentes nas atividades realizadas - apenas não se trata de uma leitura formal - e $90 \%$ tenham afirmado gostar de ler e apontam os romances $(37 \%)$ e as revistas $(24 \%)$ como os produtos mais lidos.

Em relação à educação, os resultados apontam para uma valorização da escola por parte de $63 \%$ dos respondentes, para quem a escola é uma garantia para um futuro melhor, e 78\% afirmaram que a atividade mais importante que desenvolvem hoje é estudar. Segundo $78 \%$ dos respondentes, costumam respeitar os seus professores, e $71 \%$ declararam que os professores respeitam os alunos.

Quanto à educação ministrada nas escolas públicas, na opinião de $11 \%$ dos jovens respondentes a educação é muito boa, $21 \%$ acreditam que ela seja boa, no entanto, $44 \%$ a declararam como regular, $13 \%$ a consideraram como 
ruim e $11 \%$, muito ruim. Quanto às perspectivas de futuro, apenas $17 \%$ se declararam otimistas. O poder simbólico na TV manifesta-se nos sonhos dos jovens de se tornarem jogadores famosos $(22 \%)$, atores/atrizes $(16 \%)$ e modelos de fama internacional $(9 \%)$. Apenas $16 \%$ sonham com profissões vinculadas à escola, a uma carreira acadêmica. Dentre os respondentes, $40 \%$ declararam que, se pudessem, escolheriam a profissão pela realização pessoal, em detrimento de fatores como prestígio ou dinheiro.

Quanto à discussão sobre valores e ética, 53\% dos alunos afirmam que a escola costuma discutir os acontecimentos e valores exibidos na mídia. Questionados se seus professores conversam sobre valores na escola, $43 \%$ afirmam não lembrar, $37 \%$ afirmam que às vezes conversam e $11 \%$ declaram que eles raramente o fazem. $62 \%$ não acreditam em fraternidade e $96 \%$ afirmam acreditar em solidariedade. No mês anterior à realização desse estudo, vários municípios alagoanos haviam sido parcialmente destruídos pelas chuvas e as cenas exibidas na mídia sensibilizaram a população do país. Ações de solidariedade mobilizaram a sociedade civil e manifestaram-se em campanhas de arrecadação de alimentos e agasalhos, fato que talvez explique o percentual.

Quanto aos aspectos relacionados à família, 85\% dos alunos declararam que a consideram muito importante nas suas vidas, $67 \%$ afirmam ter respeito aos seus pais e $72 \%$ afirmam respeitar suas mães. Para $59 \%$ desses jovens, o maior medo que sentem é o de perder os pais e $73 \%$ acreditam que os programas exibidos pela mídia televisiva não contribuem para a união familiar.

A relação entre o sentimento de impunidade e de ausência de leis se reflete quando os jovens são questionados sobre a confiança nos políticos do país. Apenas $8 \%$ deles responderam que concordavam completamente com a honestidade dos mesmos e apenas para $6 \%$ eles não são corruptos. Esse sentimento se reflete também no que se refere aos aspectos de justiça, desacreditada por $68 \%$ dos jovens, e da igualdade, que é desacreditada por $81 \%$ deles. A segurança também caiu em descrédito e apenas 16\% afirmam confiar completamente na polícia.

\section{Conclusões}

Os jovens afirmam gostar de assistir à televisão diariamente e a consideram como sua principal fonte de lazer. Muitos apenas citam aspectos negativos, como as cenas de violência, o consumismo, as brigas em família, os casos de corrupção; no entanto, reiteram que gostam de assistir a programas que exibem esses fatos e afirmam reconhecer os valores expostos na mídia televisiva e estabelecer a diferença com o seu cotidiano e com os seus próprios valores. 
Contudo, mesmo sem o perceber, acabam ressaltando qualidades que vêem, como a esperteza, o prestígio, o poder do dinheiro e da fama conseguidos sem muito esforço e sem os anos de escolaridade. Embora afirmem que estudar é o que fazem de mais importante, sonham com carreiras alheias ao mundo acadêmico, sonhando com status, prestígio e remuneração.

Sentem-se desconfiados e desacreditados nas autoridades do país e passam mais tempo em frente à TV, em lan houses e em bares nos fins de semana do que se preocupando com os estudos e com a construção de uma carreira, embora tenham se declarado preocupados em relação ao futuro. Uma pesquisa mais aprofundada investigaria as causas para essa desesperança e para os índices de violência que chamaram a atenção ao longo do trabalho, visto que muito deles afirmam já terem agredido ou já terem sido alvo de agressões. Percebe-se que a escola pode contribuir para a discussão em torno dos valores desses jovens, de ganhos na autoestima e da valorização desse olhar para a família e para a própria escola enquanto mantenedora de sonhos e de possibilidades. Acreditase que a mídia televisiva não tem apenas o papel de meio de comunicação, mas também de produtora de sentido, de valores e incide na concepção que os jovens têm da sua realidade e que a escola poderia contribuir para ajudar na reflexão acerca dos valores transmitidos nessa programação.

Constata-se, assim, a importância da discussão da mídia televisiva nas escolas e do poder desta, tornando imprescindível que ela não seja ignorada pelos professores, buscando contribuir para ajudar os alunos a discernir entre o mundo no qual estão inseridos e o mundo que a mídia deseja que seja visto, revelado, percebido, reafirmando a importância da formação continuada e do aperfeiçoamento docente.

\section{REFERÊNCIAS}

ADORNO, Sérgio. Violência, ficção e realidade. In: SOUZA, Mauro W. (Org.). Sujeito: o lado oculto do receptor. São Paulo: Brasiliense, 1995.

ARNALDO, Carlos A. Meios de comunicação: a favor ou contra a educação? In: CARLSSON, Ulla; FULITZEN, Cecília Von (Org.). A criança e a mídia: imagem, educação, participação. São Paulo: Cortez; Brasília: Unesco, 2002.

AUAD, Daniela. Os Parâmetros Curriculares Nacionais e os temas transversais. 2005. Disponível em: <http://www.educacaoonline.pro.br/index. php?option $=$ com_content\&view $=$ article $\&$ id $=15$ :os-parametros-curriculares- 
nacionais-e-os-temas-transversais $\&$ catid $=4$ :educacao $\&$ Itemid $=15>$. Acesso em: 10/07/2010.

BAUMAN, Z. Modernidade líquida. Rio de Janeiro: Jorge Zahar, 2001.

BOURDIEU, P. Sobre a televisão. Rio de Janeiro: Jorge Zahar, 1997.

BRITES, C. M. et. al. A importância da reflexão ética na formação do profissional de serviço social. In: BONETTI, Dilsea A. et al. (Org.). Serviço social e ética: convite a uma nova práxis. 8. ed. São Paulo: Cortez, 2007.

CHAUÍ, M. Convite à Filosofia. São Paulo: Ática, 2000.

D’AVILA, Nícia. Região Sudeste: hegemonia na mídia televisiva. Disponível em: $<$ http://www.bocc.uff.br/pag/avila-nicia-hegemonia-televisiva.pdf $>$. Acesso em: 29/06/2010.

JALES, C. A. Antropofilosofia da educação: um olhar sobre o humano (perguntas de sala de aula). João Pessoa: Ideia, 2010.

MICHEL, Maria Helena. Metodologia e pesquisa científica em ciências sociais: um guia prático para acompanhamento da disciplina e elaboração de trabalhos monográficos. São Paulo: Atlas, 2005.

PCN. Apresentação dos temas transversais. Secretaria de Educação Fundamental, Brasília, MEC/SEF, 1998. Disponível em: <http://portal.mec.gov.br/ seb/arquivos/pdf/ttransversais.pdf $>$. Acesso em: 10/07/2010.

PONCE, Branca J. A educação em valores no currículo escolar. Revista eCurriculum, São Paulo, v. 5 n. 1, p. 7-15, dez 2009. Disponível em: <http:// revistas.pucsp.br/index.php/curriculum/article/view/3255/2173>. Acesso em: 28/06/2010.

SEVERINO, Antonio J. Educação, sujeito e história. São Paulo: Olho d'Água, 2001.

TAGATA, C. M. Ética na pesquisa científica: o papel do professor na construção de um cidadão ético. Rev. Ciênc. Jur. e Soc. da Unipar, Umuarama, v. 11, n. 1, p. 115-125, jan./jun. 2008 .

TRINDADE, Judite Maria Barboza. O abandono de crianças ou a negação do óbvio. Revista Brasileira de História [online]. São Paulo, v. 19, n. 37, p. 35- 
58, set. 1999. Disponível em: <http://dx.doi.org/10.1590/S0102-018819990001 00003>. Acesso em: 29/06/2010.

WITTER, C.; PFROMM NETTO, S. A televisão e o adolescente: análise de conteúdo da programação preferida. Dissertação (Mestrado em Psicologia Escolar e do Desenvolvimento Humano) - Universidade de São Paulo, Departamento de Psicologia da Aprendizagem, do Desenvolvimento e da Personalidade. São Paulo, 1991.

Texto recebido em 06 de janeiro de 2011.

Texto aprovado em 06 de dezembro de 2011. 
